East African Medical Journal Vol. 77 No. 3 March 2000

ACUTE APPENDICITIS: AN OVERVIEW

H.S. Saidi, BSc. (Anat), MBChB and J.A. Adwok, MMed (Surg), FRCSEd., Professor, Department of Surgery, College of Health Sciences, University of Nairobi, P.O. Box 19676, Nairobi, Kenya

Request for reprints to: Professor J.A. Adwok, Department of Surgery, College of Health Sciences, University of Nairobi, P.O. Box 19676, Nairobi, Kenya

\title{
ACUTE APPENDICITIS: AN OVERVIEW
}

\author{
H. S. SAIDI and J. A. ADWOK
}

\begin{abstract}
Objective: To provide an overview of the changing epidemiology of acute appendicitis in the developed and developing countries and the presumptive reasons.

Data source: Major published series of the last two decades were reviewed using Medline Search and Index Medicus. The myriad of diagnostic approaches currently employed to reduce the hitherto high rates of negative appendicectomy were examined and current trends of management analysed.

Conclusion: The treatment modalities of acute appendicitis have undergone tremendous changes in the last decade.
\end{abstract}

\section{INTRODUCTION}

Whereas appendicular inflammation may be part of the general small or large bowel inflammation, acute appendicitis refers to a distinct entity pathologically characterised by acute transmural inflammation with peritonitis. Clinically, it is a disease with an acute onset of pain, which is initially periumbilical but later shifts to the right iliac fossa accompanied by rebound tenderness. Although it is more than 100 years since McBurney reported his study of eight patients with appendicitis, today both the aetiology and the diagnosis of this condition remain enigmatic. Despite the noted recent decline in the incidence in the Western world after the initial rise in the 19th century, appendicitis is still the commonest cause of abdominal operations(1).

The high negative appendicectomy rates with the attendant morbidity remain a source of concern. Thus, additional diagnostic tools have evolved. Many of these, however, have been characterised by limitations of low accuracy, high false negative rates and at times high costs. With the recent development in general laparoscopic surgery and its potential advantages, laparoscopic appendicectomy is seeking acceptance as the treatment of choice for early appendicitis. This paper will review the status of acute appendicitis with a view to reminding ourselves of its central place in abdominal emergency surgery.

\section{INCIDENCE}

Acute appendicitis was relatively unknown before the 19th century. Following a change in diet from cellulose based foodstuffs to foods rich in meat; its meteoric rise to become the most important abdominal disease was phenomenal. But, the diet factor could not explain everything. The fact that the disease could affect vegetarians and infants as well begged for other explanations (Table 1) for the rise(1-3). The incidence of the disease is highest in the Western world. It is put at around 15\%(4,5). In England and Wales, yearly admissions are estimated to currently stand at over 40,000 having fallen from over 100,000 in the 1960 's(5). In the USA it is estimated that 250,000 new cases of appendicitis are diagnosed yearly(6). The incidence amongst Africans and Asians has consistently been reported to be low. Reports from Africa put the incidence at around $1 \%(7-9)$.

In recent years, the incidence of the disease and mortality have been on a downward trend in developed countries, presumably because of earlier diagnosis, increasing public awareness, effective antibiotics and early surgery(10). The situation in the developing world is the opposite with some workers noting a rise in the incidence of appendicitis $(9,11,12)$, presumably because the diet in these parts of the world is today resembling more and more that of the West. The incidence of perforation has remained the same(13). The disease is commonest in the second and third decades of life and rare in the under twos and the elderly although in the latter age groups the complication rates are higher(9). Males are more affected than females and the disease is commoner in individuals of higher social status. In Africa the disease is reportedly commoner in the urban than in the rural $\operatorname{areas}(14)$.

\section{ANATOMY}

The appendix is a blind-ended tubular structure with an average length of $7.5 \mathrm{~cm}$. It is characteristically a human structure shared by only a few apes and the Australian wombat. It is longer in males and possesses a tiny lumen that admits a matchstick. It presents as an outpocketing from the caecum inferior to the ileocaecal junction with a variable position in relation to these structures. $75 \%$ of appendices are retrocaecal, $21 \%$ pelvic and the rest either post-ileal, paracaecal or pre-ileal. Attached between it and 
the ileum is the mesentery (mesoappendix). This mesentery is laden with fat in the adult and the appendicular vessels within it are only visible in the child. The appendicular and accessory appendicular arteries, branches of the ileocolic artery from the superior mesenteric artery, supply it. These vessels lie on the free border of the mesentery but may lie directly on the wall of the appendix especially where the mesentery is lacking. The vessels become endarteries once they reach the wall of the appendix. Thus thrombosis of the vessels would result in necrosis of the structure.

Table 1

Aetiological theories

\section{Lack of fibre theory}

Proposed early in the century when the disease was relatively new as a distinct entity. It received a boost in the 1970's as the disease was noted to be rare among the rural populations of developing nations. Today the theory is shaky as the falling incidence of the disease started from the 1930 's while fibre intake increased only recently. In addition, the disease is still rare among urban blacks despite their low fibre intake.

\section{Infection theory}

Bacteria are able to invade and destroy the appendix when obstructed. Faecoliths in the old and lymphatic tissue in the young obstruct the appendix causing distal stasis that predisposes to infection.

Hygiene hypothesis

This attributes the initial rise to improved sewage disposal and water supplies. This altered children's immune response to later virus infections so that they now triggered appendicitis. The same hygiene factor is however thought to explain the declining incidence. There are now fewer infections among adolescents.

Other

Breast-feeding is a marker of some unknown socio-economic factor associated with low risk of appendicitis. Potato consumption has also been curiously linked to the risk of appendicitis.

Histologically the appendix has four layers like the rest of the intestinal tract. The mucosa is columnar with crypts that contain the Kultschinksy cell. These cells give rise to carcinoids. The mucosa has aggregations of lymphoid tissue, proliferation of which may block the lumen of the appendix. The peak incidence of appendicitis in childhood, adolescents and early adulthood coincide with the period of maximal lymphoid development(10). This lymphoid tissue atrophies with age. The muscular layer has inner circular and outer longitudinal layers, the representing the convergence of taenia coli of the caecum.

The appendix develops as a derivative of the midgut loop at whose caudal limb the caecal diverticulum develops. The vermiform appendix develops as another diverticulum from the caecal diverticulum initially at the tip but because the right side of the caecum grows faster that the left wall, the appendix later comes to lie on the left wall of the caecum. Soon after the return of the midgut to the abdomen following physiological herniation, the caecum is located subhepatically and later elongates to then lie in the right iliac fossa. Failure to do this may lead to subhepatic position of the appendix in the adult(15). Other congenital anomalies of the appendix may include appendicular agenesis, duplication and left- sided appendix. The latter is seen only in cases of situs inversus.

The surface projection of the appendix is the McBurneys point located by the junction of the lateral third and medial two thirds of a line joining the umbilicus to the anterior superior iliac spine. This is classically the point of maximum tenderness in acute appendicitis and the point where appendicular incisions namely Lanz, Gridiron and Rutherford Morrison are made.

\section{PATHOLOGY}

Acute appendicitis classically presents as transmural inflammation although there are situations where only the mucosa is affected and this is termed catarrhal appendicitis whose usual course is resolution. Its exact clinical significance is, however, still contentious. Grossly, an inflamed appendix appears swollen, roughened and in severe cases appears green or even black (gangrenous appendicitis).

Histopathological features of appendicitis may be summarised as: (i) ulceration of the mucosa; (ii) polymorphonuclear cell-infiltration in all layers including the serosa; (iii) mucosal inflammation only in catarrhal appendicitis; (iv) abscess formation and; (v) mucin accumulation in appendicular mucocoele

There may also be associated inflammatory endarteritis and in upto $40 \%$ of cases, demonstrable faecoliths(5). In two Kenyan studies, Loefler(16) in Nairobi reported faecolith incidence of three per cent while Kakande in Nyeri reported an incidence of $34.6 \%(12)$. In an attempt to limit the spread of the inflammation, adjacent caecum, small intestine, large intestines and the greater omentum forming what is referred to as an appendicular mass may surround the appendix.

The results of appendicular inflammation would depend on whether the inflammation is obstructive or nonobstructive in nature. The majority of appendicitis is obstructive and may be followed by resolution, ulceration, suppuration, fibrosis or gangrene. Gangrene is twice as common in obstructed than in non-obstructed appendicitis(5). Resolution is usual in non-obstructive forms.

\section{CLINICAL FEATURES}

A patient with acute appendicitis typically presents with sudden periumbilical pain that shifts to become maximal at the right iliac fossa. There is associated anorexia, nausea and vomiting. The pain is made worse by coughing. The patient usually has mild pyrexia. This classical presentation is seen in only $50 \%$ of patients(5). Other clinical features depend on the position of the appendix. In pelvic appendicitis, the patient may present with diarrhoea and frequency. Right upper quadrant pain is a feature in subhepatic appendicitis and in a pregnant patient. The appendix shifts to the upper quadrant in pregnancy. When examined, the patient appears flushed with marked tenderness at McBurney's point. More often however, 
because of the variable position of the appendix, the point of maximum tenderness is an area at the right iliac fossa rather than a point(17). There is rebound tenderness due to local peritonitis. It is important to note that the tenderness may be significantly reduced in situations where the appendix is either pelvic or retrocaecal. The inflammed pelvic appendix may cause spasm on the psoas major and obturator internus muscles - the basis for the psoas and obturator tests for appendicitis. These signs, as is Rovsing's sign are generally unreliable in the diagnosis of appendicitis. A digital rectal examination is useful as the examiner elicits right-sided tenderness in pelvic appendicitis. A mass is palpated in the right iliac fossa in the case of an appendicular mass.

The signs of appendicitis may be difficult to appreciate in the obese patient. In late presentation of appendicitis features of complications (Table 2) are usually evident. In the child, because of a shorter omentum and difficulty in arriving at the diagnosis as the disease may only present

Table 2

Complications of appendicitis

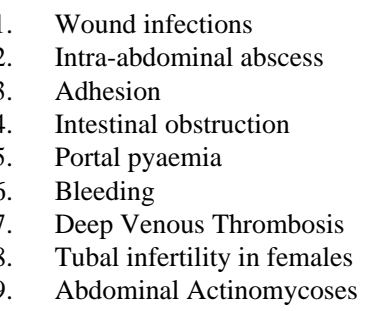

with anorexia and vomiting, perforation is common. With appendicular perforation the complication rate rises from $8 \%$ to over $30 \%(9,18)$. In the elderly, the lax abdominal wall, fatty abdomen and frequent use of enemas may explain their high complication rates.

The above symptoms and signs have formed the basis for many scoring systems for the diagnosis of appendicitis including the Alvorado, Fenyo, Teicher, Ramirez and Christian scores $(19,20)$. Table 3 shows the scoring system as advocated by Alvorado(21). Recently, Bengezi and AlFallouji described a modified Alvorado score where they replaced rebound tenderness of Alvorado with right iliac fossa rigidity and laboratory features with extra signs like the cough test, rectal tenderness and Rovsing's sign(22).

Table 3

The Alvarado scoring system for the diagnosis of appendicitisc

\begin{tabular}{lc}
\hline Component & Score \\
\hline Migration of paint & 1 \\
Anorexia & 1 \\
Nausea and vomiting & 1 \\
Tender right iliac fossa & 2 \\
Rebound pains & 1 \\
Oral temperature $>37.2$ & 1 \\
Leucocytosis & 2 \\
Neutrophils $>75 \%$ & 1 \\
\hline Total & 10 \\
\hline
\end{tabular}

\section{DIAGNOSIS}

The clinical evaluation of the patient has remained the mainstay of the diagnosis of acute appendicitis. Meticulous history and examination of the patient have direct relationship to diagnostic accuracy. Although a number of diagnostic tools including biochemical, structured data collection sheets and computer protocols have been developed to assess appendicitis, they have in the main, augmented rather than replaced clinical evaluation(23,24). Improvement in outcome has not been uniformly demonstrated with routine use of the new technology. The superiority and reliability of history and examination is most important in differentiating acute appendicitis from the other causes of acute abdomen (Table 4). Any mathematical model for diagnosis of appendicitis yields $65 \%$ accuracy but this improves to $80 \%$ with input of

Table 4

Differential diagnosis of appendicitus

Adults

Acute cholecystitis

Perforated peptic ulcer

Intestinal obstruction

Acute pancreatitis

Renal colic

Diverticular disease

Non-specific abdominal pain

Children

Non-specific abdominal pain

Mesenteric adenitis

Intussusception

Urinary tract infection

Hernia, respiratory infection

Elderly

Colorectal carcinoma

Vascular diseases

Medical causes

Women

Pelvic inflammatory disease

Urinary tract infection

Ectopic pregnancy

Twisted ovarian cyst

reliable clinical signs and symptoms. The computer-based systems are expensive and impractical. The structured data forms are easier in a clinical setting. Thus many centres today employ structured interview and examination forms to achieve the stated level of accuracy. In their recent paper, Korner et al(25) demonstrate how the use of structured data sheet improved preoperative diagnosis in their female population- a subgroup of patients in whom the diagnosis is known to be difficult.

The role of leucocytosis in the diagnosis has remained controversial. To many, its role in the diagnostic work-up is minimal as white cell response helps in suspecting 
appendicitis in only $10 \%$ of cases(16). Radiological procedures employed in the diagnosis of appendicitis include plain abdominal $\mathrm{X}$-ray and abdominal ultrasonography and the CT scan. The obliterated psoas shadow, faecolith and focal ileus that depict appendicitis in an abdominal X-ray are only seen by the most experienced radiologists. It is thus not useful to most people. The ultrasonographic method used for diagnosis of appendicitis is the graded abdominal compression technique. Features, which would suggest appendicitis, include: (i) Non-compressible appendix; (ii) Aperistaltic appendix; (iii) Appendicular diameter greater than 6mm; (iv) Circumferential loss of submucosal layer and; (v) Presence of appendicolith (faecolith)

The result of the accuracy, sensitivity and specificity of ultrasonography on the diagnosis of appendicitis has been conflicting. While some studies demonstrate high specificity of greater than $90 \%$ often results are less satisfactory on their own $(16,22)$. In the meta-analysis by Orr et al. Ultrasonography shows a sensitivity of $84.7 \%$ and specificity off $92.1 \%$ for appendicitis(27). Poor patient tolerance, obesity, gas in abdomen and unusual location of the appendix have been cited as the reasons for the reduced sensitivity(20). Combined with other diagnostic modalities, the diagnostic accuracy improves.

At the Karolinska Institute, pre-operative investigations for suspected appendicitis include abdominal ultrasound, white cell count and C-reactive protein. Studying 3037 patients retrospectively at the Institute, Styrod et al (28) reported a decline in the rate of healthy appendix.

Computerised tomography (CT) is reported to be 93$98 \%$ accurate in confirming or ruling out appendicitis $(29,30)$. The highest accuracy is with the use of helical CT after instillation of $3 \%$ diatrizoate meglumine (gastografin)-saline solution into the colon. A pendicular CT is considered safe and can be performed in approximately fifteen minutes and requires only one third of the radiation exposure of standard abdomino-pelvic CT.

Laparoscopy has recently gained more attention for its diagnostic properties and therapeutic possibilities. But the procedure is invasive and requires general anaesthesia. It is also costly. Therefore its place in the routine diagnosis of appendicitis remains to be seen.

\section{TREATMENT}

Urgent surgical removal of the inflammed appendix is the treatment of choice in most cases. This may be achieved via the open method or laparoscopically. In open appendicectomy the incisions used are Gridiron, its cosmetic equivalent (Lanz), Rutherford Morrison, lower midline or lower paramedian. The appendix is exposed or delivered, mesoappendix divided then the appendix ligated. A purse string suture may be applied on the caecum to bury the stump of the appendix. A drain is left in situ if there is plenty of purulent fluid or persistent oozing. Some centres avoid surgical removal of the appendix in the following situations: (i) Presentation more than 48 hours; (ii) Appendicular abscess and; (iii) Established mass.

In the conservative management of these latter situations, the patients are put on intravenous antibiotics, fluids, and hourly observation of vital signs and repeated abdominal examination. If the signs and symptoms improve, interval appendicectomy is carried out a few months later. In the event of perforation as evidenced by increasing pulse rate, vomiting or increasing size of mass, emergency operation is undertaken. With the advent of good antibiotics and improved handling of peritoneal sepsis, the need for interval appendectomy is becoming obsolete. Cases of success in conservative management of appendicitis in the absence of the situations cited have been described. Most of these have been in non-surgical environments. Gurin et al. describe the conservative treatment of patients on board Soviet ships(31) while Adam described conservative treatment of appendicitis in American submarines(32). In the controlled trial of appendicectomy versus antibiotics treatment Errickson et al. analysed forty patients half of whom were treated with antibiotics and the other half with surgery. All those treated conservatively were discharged after two days except one who required surgery after 12 hours. Seven were re-admitted after one year for recurrent appendicitis. They therefore concluded that antibiotic treatment was as effective as surgery save for the higher recurrence rate(33).

Laparascopic appendicectomy has evolved to become the operation of choice for early appendicitis in some western centres. It is thought to facilitate the diagnosis of a patient with suspected appendicitis offer a better post operative course and add little to morbidity when compared to open procedures(34). Analysing 8651 appendectomy operations carried out in England and Wales, Baigrie et al. found that $1.2 \%$ of the procedures were laparascopic. The patient's hospital stay was 4.1 days after open surgery compared to 2.4 days after laparascopic surgery(13). In a recent review of randomized control trials comparing laparoscopic with open appendectomy, McCall and his colleagues found that the laparoscopic procedure is associated with a longer operating time, minimal reduction in hospital stay, reduced rate of wound infection with no increase in other complications(35). In the similar study of Mutter et al. there was no difference in post-operative pain, time of discharge or complications between men randomised to open or laparoscopic appendicectomy(36). With the findings from these randomised studies therefore, it remains to be seen whether laparoscopic appendectomy can indeed evolve to become the gold standard treatment for acute appendicitis. Results of recent studies that demonstrate the feasibility and safety of early discharge after open appendectomy $(37,38)$ only complicates matters for the proponents of laparascopic appendicectomy. Further, absence of surgeons trained in laparoscopic work in the late hours of the night when the majority of diagnosis and treatment of appendicitis is undertaken, lack of 
laparoscopic equipment in many emergency theatres and support staff would ensure that open appendicectomy remains the commonest operation for appendicitis for a long time.

\section{REFERENCES}

1. Heaton, K.W. Aetiology of acute appendicitis. Brit. J. Surg. 1987; 294: 1632-1633.

2. Baker, D.J.P. Acute appendicitis and dietary fibre; an alternative hypothesis. Brit. J. Surg. 1985; 290: 1125-1127.

3. Alfredo, P., de Luca, U., Impaabiazzo, N., Russo, M., De Caprio, C. and Carraciolo, G. Appendicitis and infant feeding. Brit. Med. J. 1995; 310: 836-837.

4. Yerzingatsan, K.L. The incidence of open appendicectomy, herniorrhaphy and cholecystectomy in four hospitals of the underdeveloped world and discussion on the role of minimal access surgery.J. roy. Coll. Surg. Edin. 1997; 42: 329-330.

5. Krukowski, Z.H., O'Kelly, T.J. Appendicitis. Surgery. 1997; 15: 76-81.

6. Addis, D.G., Shaffer, N., Fowler, B.S. and Tauxe, R.V. The Epidemiology of appendicitis and appendectomy in the United States. Amer. J. Epidem. 1990; 132: 910-25.

7. Walker, A.R.P., Richardson, B.P. Walker, B.F. and Woodford, A. Appendicitis, fibre intake and bowel habits in ethnic groups in South Africa. Postgrad. Med J. 1973; 49: 243-248.

8. Otu, A.A. Tropical Surgical abdominal emergencies: Acute appendicitis Trop. geogr. Med. 1989; 4: 118-122.

9. Madiba, T.E., Haffejee, A.A., Mbete, D.L.M., Chalthram, H. and John, J. Appendicitis among African patients at King Edward VIII Hospital, Durban, South Africa: A Review. East Afr. Med. J. 1998; 75: 81-84.

10. Mann, C.V. The Vermiform appendix. In: Short textbook of Surgery. 22nd edition 1995; 52: 828-841.

11. Ahmed, M.E., Acute appendicitis in Khartoum: Pattern and clinical presentation. East Afr. Med J. 1978; 55: 172.

12. Kakande, I. and Nehra, M.K. Appendicectomy in Consolata Hospital, Nyeri: analysis of operative and histological findings. East Afr. Med. J. 1990; 67: 573 -576.

13. Baigrie, R.J., Dehn, T.C.B. and Fowler, S.M., Dunn Analysis of 8651 appendicectomies in England and Wales during 1992. Brit. J. Surg. 1995; 82: 933.

14. Moore, S.W. and Robbs, J.V. Acute appendicitis in the Zulu an emerging disease? S. Afr. Med. J. 1979; 55: 100.

15. Moore, K.L. The Developing Human, Clinically oriented embryology. W.B. Saunders. 1982, pp. 242.

16. Loefler, I.J.P. Appendicitis and appendicectomy. Proc. Assoc. Surg. E. Afr. 1983; 6: 135.

17. De Dombal, F.T. Marguiles, M. Acute abdominal Pain. Surgery. 1996; 33: 97-102.

18. Calder, J.D.F., Gajra, J H. Recent advances in the diagnosis and treatment of acute appendicitis. Brit. J. Hosp. Med. 1995; 54: 129-33.

19. Ohman, C. Yang, Q. and Franke, C. Diagnostic scores for acute appendicitis. Abdominal pain study group. European J. Surg. 1995; 161: 273-81.

20. Gallego, M.G., Fadrique, B. and Nieto, M.A., et al. Evaluation of Ultrasonography and Clinical diagnostic scoring in suspected appendicitis. Brit. J. Surg. 1998; 85: $37-40$.

21. Alvorado, A.A. A practical score for the early diagnosis of appendicitis. Ann. Emerg. Med. 1986; 15: 557-64.

22. Bengezi, O.A. and Al-Fallouji, M. Modified Alvorado score in diagnosis of acute appendicitis. Brit. J. Surg. 1997; 84: 30 .

23. Wilcox, R.T. and Traverso, L.W. 'Have the evaluation and treatment of acute appendicitis changed with new technology?' Surg. Clin. N. Amer. 1997; 77: 1355-70.

24. Hidalgo, L.A., Heredia, A. Casals, S., Pros, I., Badra, J.M. and Gubern, J.M. Is routine Ultrasonography useful in the diagnosis of acute appendicitis. A prospective study. Brit. J. Surg. 1995; 82: 6 .

25. Korner, H., Sondenaa, K., Soreide, J.A., Andersen, E., Nysted, A. and Lende, T.H. Structured data collection improves diagnosis of acute appendicitis. Brit. J. Surg. 1998; 85: 341-344.

26. Jeffrey, R.B. Jr, Laing, F.C. and Townsend, R.R. Acute appendicitis: Sonographic criteria based on 250 cases. Radiology. 1988; 167: 327-9.

27. Orr, R.K., Porter, D. and Hartman, D. Ultrasonography to evaluate adults for appendicitis; decision making based on meta-analysis and probabilistic reasoning. Acad Emerg. Med. 1995; 2: 644-50.

28. Styrod, J., Eriksson, S. and Ganstrom, L. Diagnostic accuracy inpatients with appendicitis. Analyses in 2352 patients during 8 years. Brit. J. Surg. 1995; 82: 8.

29. Balthazar, E.J., Bronbaum, B.A., Yee, J., Megipow, A.J., Roshkow, J. and Gray C. Acute appendicitis: CT and US correlation in 100 patients. Radiology. 1994; 190: 31-35.

30. Rao, P.M., Rhea, J.J., Novelline, R.A. Mostafari, A.A. and McCabe, C.J. Effect of Computerised tomography of the appendix on treatment of patients and use of hospital resources. N. Eng. J. Med. 1998; 338: 141-6.

31. Gurln, N.N., Slobodchuk, I.U.S. and Gavrilov, I.V.F. The efficacy of conservative treatment of patients with acute appendicitis on board ships at sea. Vestn Khir. 1992; 148: 144-50.

32. Adam, M.L. The medical management of acute appendicitis in a non-surgical environment: a retrospective case review. Milit. Med. 1990; 155: 345-7.

33. Errikson, S. and Ganstrom, L. Randomized controlled trial of appendectomy versus antibiotic therapy for acute appendicitis. Brit. J. Surg. 1995; 82: 166-169.

34. Taylor, H.W. and Wellwood, J.M. Principles and present status of Laparoscopic general Surgery. Surgery. 1997;15: 73-75.

35. McCall, L.K., Sharples, K. and Jadallah, F. Systemic randomized controlled trials comparing laparoscopic with open appendicectomy. Brit. J. Surg. 1997; 84:1045-1050.

36. Mutter, D, Vix M, Bui, et al. Laparoscopy is not recommended for routine appendectomy in men: results of a prospective randomized study. Surgery. 1996;120: 71-4.

37. Ramesh, S. and Galland, R.B. Early discharge from hospital after open appendicectomy. Brit. J. Surg. 1993;80:1192-3.

38. Lord, R.V. and Sloane, D.R. Early discharge after open appendicectomy. Aust. N. Z. J. Surg. 1996; 66: 361-5. 